\title{
Natural infection of the feline lungworm Aelurostrongylus abstrusus in the invasive snail Achatina fulica from Argentina
}

\author{
Romina Valente ${ }^{a, *}$, Julia Ines Diaz ${ }^{b}$, Oscar Daniel Salomón ${ }^{a}$, Graciela Teresa Navone ${ }^{b}$ \\ a Instituto Nacional de Medicina Tropical (INMeT), Jujuy s/n, 3370 Puerto Iguazú, Misiones Province, Argentina \\ b Centro de Estudios Parasitológicos y de Vectores (CEPAVE), Facultad de Ciencias Naturales y Museo, Universidad Nacional de La Plata, CONICET, calle 120 \\ e/61 y 62, B1900FWA La Plata, Buenos Aires Province, Argentina
}

\section{A R T I C L E I N F O}

\section{Article history:}

Received 3 August 2016

Received in revised form 7 December 2016

Accepted 9 January 2017

\section{Keywords:}

Puerto Iguazú

Achatina fulica

Intermediate host

Metastrongyloidea

Aelurostrongylus abstrusus

Aelurostrongilosis

\begin{abstract}
A B S T R A C T
The giant African snail Achatina fulica is an invasive mollusk native to Africa, the first record in Argentina was in Puerto Iguazú, in northeastern Argentina in 2010. Recently it was reported in Corrientes Province. This snail can act as an intermediate host of Metastrongyloidea nematodes of importance in public health as: Angiostrongylus cantonensis, Angiostrongylus costaricensis and Angiostrongylus vasorum. Taking into account the presence of A. fulica in Argentina, the objectives of this study is to assess the presence of Metastrongyloidea nematodes in this mollusk species in Puerto Iguazú, Misiones, close to the international border with Brazil and Paraguay. A total of 451 samples were collected from February 2014 to November 2015. The snails were processed using a digestion technique to recover the parasites. A total of 206 nematodes larvae were founded in the digestion solution of 10 hosts ( $P=2 \% ; M A=0.5 ; M I=21)$. Third larval stage (L3) nematodes identified as Aelurostrongylus abstrusus were founded parasitizing the snails. No other larval stage was observed. This species has veterinary importance because it causes 'aelurostrongilosis', also known as feline strongyloidosis. This study constitutes the first record of a Metastrongyloidea nematode in A. fulica in Argentina and also highlights the susceptibility of this mollusk as intermediate host of other helminthes of health importance. The present study suggests that there is a need to establish an epidemiological monitoring system in order to prevent the possible installation of an infected mollusks focus.
\end{abstract}

(C) 2017 Elsevier B.V. All rights reserved.

\section{Introduction}

Achatina fulica Bowdich, 1822 (Gastropoda: Achatinidae) is a land pulmonate mollusk native to north-east Africa and widely distributed in Brazil nowadays. Achatina fulica was first recorded in Argentina in Puerto Iguazú city, Misiones Province, in 2010 (Gutiérrez Gregoric et al., 2011). Later, the species was reported in Corrientes Province, southern to Misiones (Gutiérrez Gregoric et al., 2013). The introduction of this mollusk in Argentina is probably related to its proximity to Brazil and to fishing practices. Achatina fulica is important for public health because it can act as intermediate host of different species of Metastrongyloidea nematodes such as Angiostrongylus cantonensis and Angiostrongylus costaricensis, causing eosinophilic meningoencephalitis and abdominal angiostrongylosis (Thiengo et al., 2007; Maldonado et al., 2010; Oliveira et al., 2010); Angiostrongylus vasorum, infecting

\footnotetext{
* Corresponding author.

E-mail address: romina_valente81@hotmail.com (R. Valente).
}

the pulmonary artery and the right ventricle of wild and domestic canids, and Aelurostrongylus abstrusus causing "aelurostrongilosis" in felids.

The presence of $A$. abstrusus is associated with some symptoms as coughing, sneezing, wheezing, dyspnea, ocular-nasal discharge and progressive weight loss. The adult worms live in the terminal respiratory bronchioles and alveolar ducts, thus produces several subclinical granulomatous pneumonia in cats (Headley, 2005). The aelurostrongylosis may be asymptomatic, subclinical or clinically manifested depending on the worm burden, age and immune response of the infected animal (Traversa and Guglielmini, 2008).

The life cycle of $A$. abstrusus involves two hosts. Adult nematodes live in the respiratory system of the felid definitive host. The first stage larvae go up to the trachea, where they are swallowed, and then excreted in the faeces. The larvae penetrate terrestrial mollusks, in which they continue their development to the third larval stage. Paratenic hosts such as frogs, birds or lizards eat the infected mollusk and act as transport for the third larval stage. Definitive host becomes infected by the ingestion of infected mollusk or paratenic host. 
Aelurostrongylus abstrusus has a wide geographical distribution (Bjork et al., 2000; Sommerfelt et al., 2006; Ferrerira et al., 2007; Traversa et al., 2008; Barutzki and Schaper, 2013). In Argentina, adults of this species have been reported in domestic cats in Buenos Aires, Corrientes and Santa Fe provinces (Lombardero and Días, 1967; Idiart et al., 1986; Santa Cruz and Lombardero, 1987; Schiaffi et al., 1995).

Several gastropods have been reported as intermediate host of $A$. abstrusus: Subulina sp.; Arion sp.; Cernuella virgata; Achatina fulica; Helix aspersa and Rumina decollata (Hobmaier and Hobmaier, 1935; López et al., 2005; Thiengo et al., 2008; Ohlweiler et al., 2010; Di Cesare et al., 2013; Cardillo et al., 2014).

Taking into account the presence of A. fulica in Argentina, the objectives of this study is to assess the presence of Metastrongyloidea nematodes in this mollusk species in Puerto Iguazú, Misiones, close to the international border with Brazil and Paraguay.

\section{Materials and methods}

\subsection{Study area}

This study was carried out in Puerto Iguazú $\left(25^{\circ} 36^{\prime} 39^{\prime \prime} \mathrm{S}\right.$, $54^{\circ} 34^{\prime} 49^{\prime \prime}$ W), Misiones Province, Argentina. The climate in this region is subtropical, with a mean annual temperature of $22^{\circ} \mathrm{C}$ and an average annual rainfall of $2000 \mathrm{~mm}$.

\subsection{Sampling and examination of Achatina fulica}

A total of $451 \mathrm{~A}$. fulica were seasonally collected from February 2014 to November 2015. Snails were always collected manually and by the same two people. Collecting trips lasted thirty minutes.

Samples were transported alive in plastic vials to the laboratory where each snail was placed in a container. After $24 \mathrm{~h}$, every shell was broken and the cephalopodal mass was separated and individually placed in a beaker. The cephalopodal mass were minced and digested with pepsin (4mg\%) in $0.7 \mathrm{HCL}$ solution for $4 \mathrm{~h}$ at $37^{\circ} \mathrm{C}$ (Wallace and Rosen, 1969). The digested samples were placed in funnels and allowed to sediment for $6 \mathrm{~h}$ prior to examination. From each sample, $10 \mathrm{ml}$ of the digested solution were taken and centrifuged for $5 \mathrm{~min}$ at 1800 r.p.m. The content was placed on a glass slide and examined under light microscope Trino Arcano ZTX.

\subsection{Study of parasites}

Recovered nematodes larvae were fixed in alcohol formalin acid solution AFA and studied using a light microscope Olympus BX51 ${ }^{\circledR}$. They were measured and drawn with the aid of a camera lucida and photographs were taken with a Q-Imaging Go-3 camera.

Taxonomic identification was based on morphometric parameters following specific bibliography (Ash, 1970; Thiengo et al., 2008; Anderson et al., 2010; Andrade-Porto et al., 2012). Prevalence (P), mean abundance (MA) and mean intensity (MI) were calculated (Bush et al., 1997). Measurements are given in micrometers $(\mu \mathrm{m})$, range followed by arithmetic mean in parentheses. Voucher specimens were deposited in the Helminthological Collection of Museo de La Plata (MLP HeXXX).

\section{Results and discussion}

From a total $451 A$. fulica examined, 206 nematodes larvae were found in the digestion solution of 10 hosts $(P=2 \%$; $M A=0.5$; $\mathrm{MI}=21$ ). The number of parasites ranged from 1 to 100 .

The presence of a stiletto in the anterior extremity and a rounded button ("knobed") in the posterior extremity (Fig. 1), allow as to

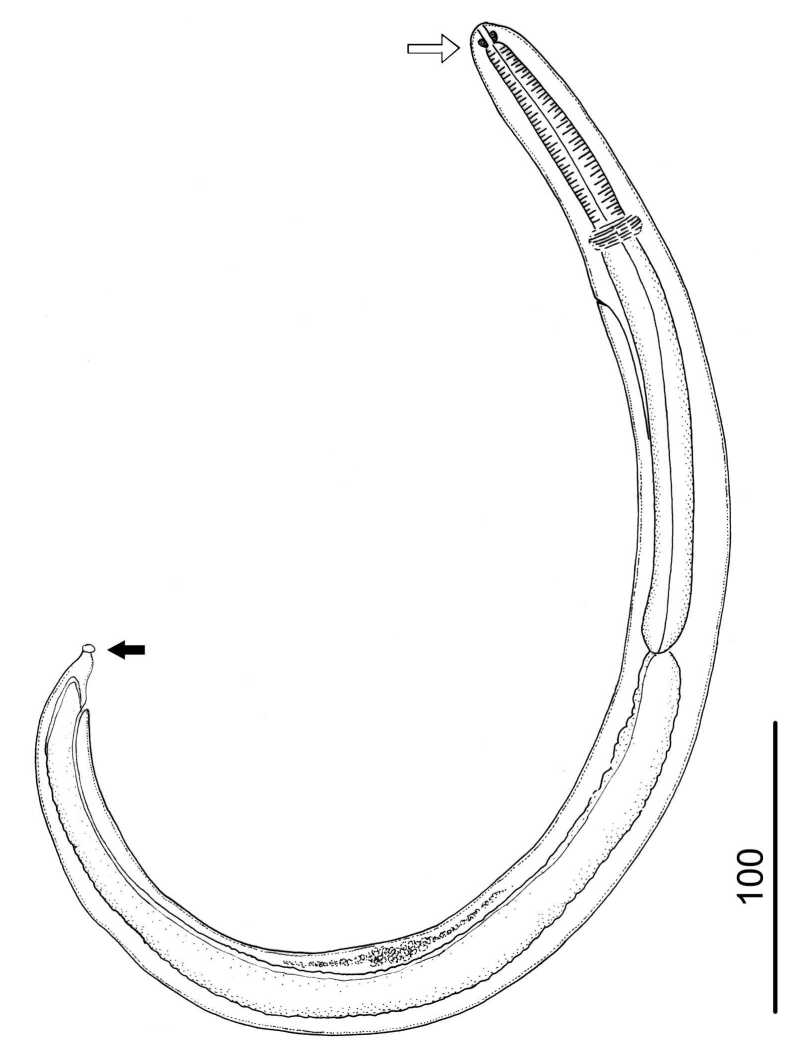

Fig. 1. $\mathrm{XXX}$

identify this larvae as Aelurostrongylus abstrusus L3. Larvae had a large and cylindrical muscular oesophagus and one or two cuticular sheaths. The nerve ring was not observed. No other larval stage was observed.

Measurements of present specimens and those provided by previous authors are detailed in Table 1.

Measurements of L3 of A. abstrusus observed in A. fulica are slightly different of that observed in Cernuella (Cernuella) virgata and Helix aspersa. It could be due because the development of the parasites are influenced by features of the snail species. It is known that the size of parasites may be influence by its permanence within the host; therefore older (larger) host will have large parasites (López et al., 2005; Di Cesare et al., 2013; Giannelli et al., 2014). Difference on size observed between L3 of $A$. fulica reported by Andrade-Porto et al. (2012) and those of present study could be explain because the size of the former snails were smaller than those studied in the present study (less than $5 \mathrm{~cm} v s$ more than $6 \mathrm{~cm}$ respectively).

Geographic expansion of the lungworms in the last years can be explained for the climate change that may have influence in the host - parasite relationships. The population dynamics of gastropod are influenced by abiotic factors as temperature and humidity (Jenkins et al., 2006). Taking account that snails play a very important role as spreaders of lungworms (Koch and Willesen, 2009), a geographic increase of the suitable environmental conditions for the snails bring on the occurrence of "aleurostrongiliasis" in new geographical areas.

The presence of the giant African snail A. fulica in Puerto Iguazú is considered alarming, not only for its effect on the native mollusk populations, but also for its role as intermediate host of parasites of medical and veterinary importance. This study constitutes the first record of a Metastrongyloidea nematode in A. fulica in Argentina and also highlights the susceptibility of this mollusk as intermediate host of other helminths of health importance. 
Table 1

Measurements of Aelurostrongylus abstrusus L3 in different host species (Measurements = range followed by the mean).

\begin{tabular}{|c|c|c|c|c|c|}
\hline References & López et al. (2005) & Thiengo et al. (2008) & Andrade-Porto et al. (2012) & Giannelli et al. (2014) & Present study \\
\hline Locality & Spain & Brazil & Brazil & Italy & Argentina \\
\hline Host & C. virgata & A. fulica & A. fulica & H. aspersa & A. fulica \\
\hline Total length & $576-640(608)$ & $546-602(583)$ & $330-416(387)$ & $488-590(539)$ & $500-635(562)$ \\
\hline Maximum width & - & - & - & $25-28(27)$ & $23-38(30)$ \\
\hline Excretory pore (fae) & $94-123(109)$ & $95-103(101)$ & $48-76(58)$ & $87-98(92)$ & $90-99(95)$ \\
\hline Esophagus length & $176-236(206)$ & $198-218(206)$ & $130-174(156)$ & $183-210(202)$ & $190-215(201)$ \\
\hline Genital primordium (fpe) & $182-235(209)$ & - & - & - & $150-180(170)$ \\
\hline Anus & $37-47(42)$ & $39-42(41)$ & $20-32(25)$ & $34-40(36)$ & $20-35(29)$ \\
\hline
\end{tabular}

fae $=$ Distance from the anterior end; fpe=Distance from the posterior end to the anus.

Considering all the aspects mentioned, the present study suggests that there is a need to establish an epidemiological monitoring system in order to prevent the possible installation of an infected mollusks focus.

\section{Acknowledgements}

We wish to thank M.C. Estivaríz (CEPAVE) for her help with the drawings, M.L. Morote (CEPAVE) for the Graphical Abstract and Pilar Martínez (National Public Translator in English Language) for the English revision of the manuscript. This study was partially found by UNLP (N751).

\section{References}

Anderson, R.C., Chabaud, A.G., Wilmott, S., 2010. Keys to the Nematode Parasite of Vertebrates. Archival Volume, 1st ed. CABI International, Wallingford, UK, pp. 200.

Andrade-Porto, S.M., Pereira de Souza, K.C., Cardenas, M.Q., Roque, R.A., Pimpao, D.M., Araujo, S.C., Oliveira Malta, J.C., 2012. Occurrence of Aelurostrongylus abstrusus (Railliet, 1898) larvae (Nematoda: metastrongylidae) infecting achatina (Lissachatina) fulica bowdich, 1822 (Mollusca: gastropoda) in the amazon region. Acta Amaz. 42, 245-250.

Ash, L., 1970. Diagnostic morphology of the third.stage larvae of Angiostrongylus cantonensis, Angiostrongylus vasorum, Aelurostrongylus abstrusus, and Anafilaroides rostratus (Nematoda Metastrongyloidea). J. Parasitol. 56, 249-253.

Barutzki, D., Schaper, R., 2013. Occurrence and regional distribution of Aelurostrongylus abstrusus in cats in Germany. Parasitol. Res. 112, 855-861.

Bjork, K., Averbeck, G., Stromberg, B., 2000. Parasites and parasite stages of free-ranging wild lions (Panthera leo) of northern Tanzania. J. Zoo Wildl. Med. $31,56-61$.

Bush, A.O., Lafferty, K.D., Lotz, J.M., Shostakll, A.W., 1997. Parasitology meets ecology on its own terms. J. Parasitol. 83, 575-583 (Margolis et al. revisited)

Cardillo, N., Clemente, A., Pasqualetti, M., Borrás, P., Rosa, A., Ribicich, M., 2014. First report of Aelurostrongylus abstrusus in domestic land snail Rumina decollata, in the Autonomous city of Buenos Aires. InVet 16, 15-22.

Di Cesare, A., Crisi, P.E., Di Giulio, E., Veronesi, F., Di Regalbono, A.F., Talone, T. Traversa, D., 2013. Larval development of the feline lungworm Aelurostrongylus abstrusus in Helix aspersa. Parasitol. Res. 112, 3101-3108.

Ferrerira, A., Dantas, L., Labarthe, N., 2007. Registro de um caso de Aelurostrongylus abstrusus em um gato domestic no Rio de Janeiro, RJ. Braz. J. Vet. Res. Anim. Sci. 44, 24-26.

Giannelli, A., Ramos, R., Annoscia, G., Di Cesare, A., Colella, V., Brianti, E., Dantas-Torres, F., Mutafchiev, Y., Otranto, D., 2014. Development of the feline lungworms Aelurostrongylus abstrusus and Troglostrongylus brevior in Helix aspersa snails. Parasitology 141, 563-569.

Gutiérrez Gregoric, D.E., Nuñez, V., Vogler, R.E., Rumi, A., 2011. Invasion of the Argentinean Paranense rainforest by giant African snail, Achatina fulica. Am. Malac. Bull. 29, 135-137.

Gutiérrez Gregoric, D., Beltramino, A., Vogler, R., Rumi, A., 2013. Expansión del rango de distribución de Achatina fulica (Gastropoda) y su concordancia con modelos predictivos. Amici Molluscarum 21, 17-21.
Headley, S.A., 2005. Aelurostrongylus abstrusus induced pneumonia in cats: pathological and epidemiological findings of 38 cases (1987-1996). Semina: Ciências Agrárias 26, 373-380.

Hobmaier, M., Hobmaier, A., 1935. Intermediate hosts of Aelurostrongylus abstrusus of the cat. Exp. Biol. Med. 32, 1641-1646.

Idiart, J., Martín, A., Venturini, L., Ruager, J., 1986. Neumonía por Aelurostrongylus abstrusus en gatos: primeros hallazgos en el gran buenos aires y La plata. Rev. Vet. Argent. 3, 229-237.

Jenkins, J.E., Veitch, A.M., Kutz, S.J., Hoberg, E.P., Polley, L., 2006. Climate change and the epidemiology of protostrongylid nematodes in northern ecosystems: parelaphostrongylus odocoilei and Protostrongylus stilesi in Dall's sheep (Ovis d. dalli). Parasitology 132, 387-401.

Koch, J., Willesen, J.L., 2009. Canine pulmonary angiostrongylosis: an update. Vet. J. $179,348-359$.

López, C., Panadero, R., Paz, A., Sánchez-Andrade, R., Díaz, P., Díez-Baños, P., Morrondo, P., 2005. Larval development of aelurostrongylus abstrusus (Nematoda, angiostrongylidae) in experimentally infected cernuella (Cernuella) virgata (Mollusca, helicidae). Parasit. Res. 95, 13-16.

Lombardero, O., Días, B., 1967. Primeros casos de aelurostrongylus abstrusus (Raillet, 1898) en la rgentina (Nematoda: metastrongylidae). Rev. Med. Vet. 48, 279-283.

Maldonado Júnior, A., Simoes, R., Oliveira, A.P., Motta, E.M., Fernandez, A.M., Pereira, Z.M., Monteiro, M.M., Lopes Torres, E.J., Carvalho Thiengo, S., 2010 First report of Angiostrongylus cantonensis (Nematoda: metastrongylidae) in achatina fulica (Mollusca: gastropoda) from southeast and south Brazil. Mem. Inst. Oswaldo Cruz 105, 938-941.

Ohlweiler, P.F., Yoshika Takahashi, F., Guimaraes, M., Rodrigues Gomes, S., Kawano, T., 2010. Manual de Gastropodes limnicos e terrestres do Estado de San Pablo asociados as helmintoses: Redes, 95-119.

Oliveira, M.A., Torres, E., Maldonado Jr, A., Araujo, J., Fernandez, M., Carvalho Thiengo, S., 2010. Achatina fulica como hospedador intermediario de nematodes de interés sanitario-veterinario en Goias. Brasil Rev. Patol. Trop. 39, 199-210.

Santa Cruz, A., Lombardero, O., 1987. Primeros hallazgos en el Nordeste de Aelurostrongylus abstrusus (Raillet, 1911) adultos en gatos. Rev. Vet. Argent. 4 155-157.

Schiaffi, A., Bela, M., Bola, L., Peruzzo, L., 1995. Aelurostrongylus abstrusus: diagnostico en la ciudad de Rosario. Rev. Vet. Argent. 12, 480-483.

Sommerfelt, I.E., Cardillo, N., López, C., Ribicich, M., Gallo, C., Franco, A., 2006. Prevalence of Toxocara cati and other parasites in cats' faeces collected from the open spaces of public institutions: Buenos Aires, Argentina. Vet. Parasitol. 140, 296-301.

Thiengo, C.S., Faraco, A.F., Salgado, N.C., Cowie, R.H., Fernandez, M.A., 2007. Rapid spread of an invasive snail in South America: the giant African snail Achatina fulica. Biol. Invasions 9, 693-702.

Thiengo, C.S., Fernandez, M.A., Torres, E.J.L., Coelho, P.M., Lanfredi, R.M., 2008. First record of a nematode metastrongyloidea (Aelurostrongylus abstrusus larvae) in Achatina (Lissachatina) fulica (Mollusca, achatinidae) in brazilian. J. Invertebr. Pathol. 98, 34-39.

Traversa, D., Guglielmini, C., 2008. Feline aelurostrongylosis and canine angiostrongylosis: a challenging diagnosis for two emerging verminous pneumonia infections. Vet. Parasitol. 157, 163-174.

Traversa, D., Lia, R., Iorio, R., Boari, A., Paradies, P., Capelli, G., Avolio, S., Otranto, D., 2008. Diagnosis and risk factors of Aelurostrongylus abstrusus (Nematoda: strongylida) infection in cats from Italy. Vet. Parasitol. 153, 182-186.

Wallace, G., Rosen, L., 1969. Techniques for recovering and identifying larvae of Angiostrongylus cantonensis from molluscs. Malacologia 7, 427-438. 